\section{Anaphylactic reaction to radioimmunotherapy despite plasmapheresis to remove anti-mouse antibodies}

\author{
$M \mathrm{~J}$ Verhaar-Langereis $\mathrm{MD} \mathrm{PhD}^{1}$ \\ $P$ A Keep $P h D^{2} \quad J L$ Casey $P h D^{2}$ \\ $\mathrm{R} \mathrm{H} \mathrm{J} \mathrm{Begent} \mathrm{FRCP} \mathrm{FRCR}{ }^{2}$
}

K F Eagle MRCP ${ }^{2}$

J R Soc Med 2000;93:75-76

Radioimmunotherapy (RIT) is a method by which radiation (radionuclide) is selectively delivered to its target by means of monoclonal antibodies, usually of mouse origin. Repetition of the treatment may improve response rates, but is limited by the development of human anti-mouse antibodies (HAMA), which are detectable in up to $50 \%$ of patients after a single injection ${ }^{1,2}$. The presence of HAMA in the serum leads to immune complex formation on reexposure to the mouse antibody, with rapid clearance of the complex through liver and spleen and the risk of acute hypersensitivity reactions. Immunosuppression with cyclosporin can delay the production of $\mathrm{HAMA}^{1,3}$, and plasmapheresis has been used to reduce HAMA titres sufficiently to allow further RIT ${ }^{4}$.

\section{CASE HISTORY}

A man aged 62 with liver metastases from a previously resected rectal carcinoma was treated with two courses of RIT. He had no history of atopy. The antibody used was $\mathrm{F}\left(\mathrm{ab}^{\prime}\right)_{2}$ fragment of the monoclonal anticarcinoembryonic antibody-A5B75 $.100 \mathrm{mCi}$ of ${ }^{131}$ I-labelled antibody $(10 \mathrm{mg})$ was given intravenously in 25 minutes. Radioiodination was performed by the N-bromosuccinide method ${ }^{6}$. Concomitant oral cyclosporin was administered to prevent HAMA formation (serum levels 213-577 $\mu \mathrm{g} / \mathrm{L}$ ). A complete response, lasting 5 weeks, was seen after the first course of treatment and overall he had a partial response by World Health Organization criteria after two cycles of RIT. No further RIT was given because of the development of HAMA, detected by an enzyme immunoassay ${ }^{1}$. Seven

${ }^{1}$ Department of Internal Medicine, University Hospital Utrecht, The Netherlands ${ }^{2}$ CRC Department of Clinical Oncology, Royal Free Hospital School of Medicine, Pond Street, London NW3 2QG, UK

Correspondence to: Marlies J Verhaar, University Hospital Utrecht, Heidelberglaan 100, 3584 CX Utrecht, The Netherlands months later he relapsed with rising tumour markers and enlarging liver metastases which proved unresponsive to chemotherapy with folinic acid and 5-fluorouracil. Ten months after this relapse, to allow further RIT, he underwent plasma exchange on two consecutive days before antibody administration. On both days three litres of plasma was replaced by three litres of human albumin $4.5 \%$ containing 10\% calcium gluconate. Afterwards no HAMA IgG was detected in the patient's serum by enzyme immunoassay in triplicate (Figure 1) and a skin test was negative. An infusion of ${ }^{131} \mathrm{I}-\mathrm{A} 5 \mathrm{~B} 7 \mathrm{~F}\left(\mathrm{ab}^{\prime}\right)_{2}$ was then started but after five minutes the patient became acutely hypotensive with tachycardia followed by cardiac collapse. The infusion was stopped immediately and he was successfully resuscitated.

To investigate the probable cause of this reaction, serum before and after plasmapheresis was analyzed to identify immune complexes by use of S-300 column chromatography (Pharmacia, St Albans, UK) ${ }^{3}$. Figure 2 shows a single peak at a higher molecular weight than the free $\mathrm{F}\left(\mathrm{ab}^{\prime}\right)_{2}$, confirming the presence of a complex between the $\mathrm{F}\left(\mathrm{ab}^{\prime}\right)_{2}$ antibody and HAMA in the patient's serum taken before plasmapheresis. After plasmapheresis the elution profile of the incubated serum shows two peaks at different molecular weights (Figure 2). The smaller peak at the lower molecular weight is equivalent to free $\mathrm{F}\left(\mathrm{ab}^{\prime}\right)_{2}$ and the larger peak at the higher molecular weight suggests the presence of an immune complex.

\section{COMMENT}

How can we account for this patient's anaphylactic reaction when enzyme immunoassay after plasmapheresis detected no HAMA $\operatorname{IgG}$ in his serum? The S-300 profile of the serum after plasmapheresis demonstrated free $\mathrm{F}\left(\mathrm{ab}^{\prime}\right)_{2}$ and a second peak of higher molecular weight indicating that the $\mathrm{F}\left(\mathrm{ab}^{\prime}\right)_{2}$ was complexing with the patient's serum. This complex

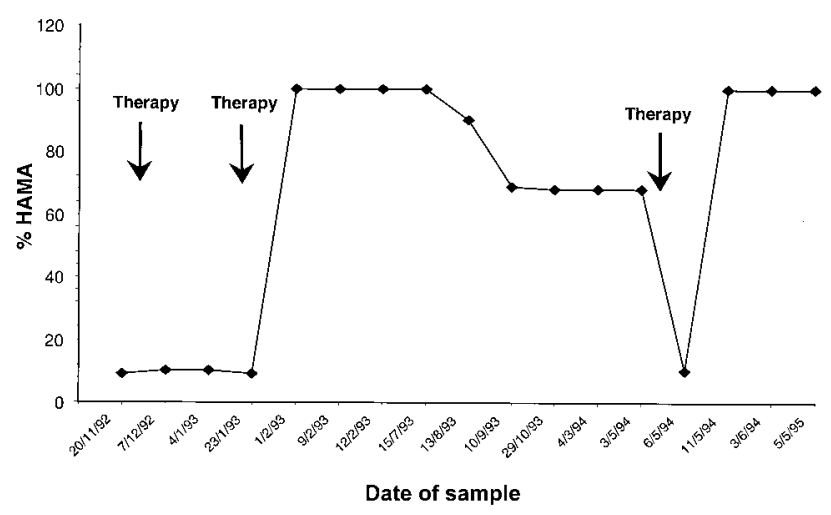

Figure 1 HAMA profile measured by ELISA. Results are expressed as a percentage of HAMA 


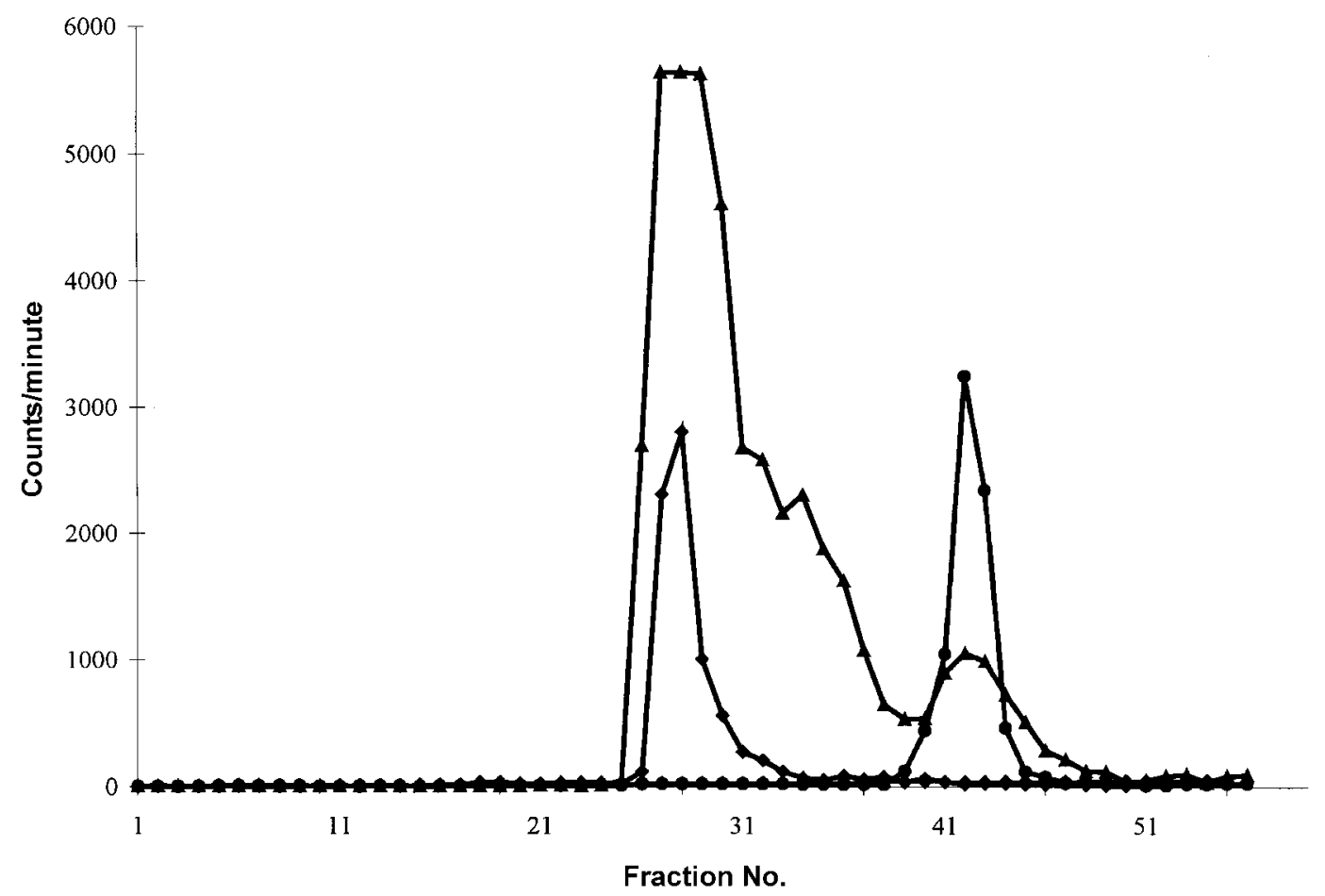

Figure 2 S-300 elution profile of ${ }^{131} \mathrm{I}-\mathrm{F}\left(\mathrm{ab}^{\prime}\right)_{2}$ incubated with serum before and after plasmapheresis.

Before plasmapheresis $(\bullet)$; after plasmapheresis $(\mathbf{\Lambda})$. The third curve $(\bullet)$ demonstrates the elution profile of ${ }^{131} \mathrm{I}-\mathrm{F}\left(\mathrm{ab}^{\prime}\right)_{2}$ antibody incubated with serum of a patient without HAMA

was unlikely to be due to binding of the $\left.\mathrm{F}(\mathrm{ab})_{2}\right)_{2}$ antibody to circulating carcinoembryonic antigen in the serum since these levels were low $(<100 \mu \mathrm{g} / \mathrm{L})$. In addition, the molecular weight of the immune complex was too low for it to be an IgM molecule in the patient's serum. We therefore postulate that this could be an IgE antibody in the absence of $\operatorname{IgG}$. The serum IgE before plasmapheresis was $628 \mathrm{kIU} / \mathrm{L}$, falling to $320 \mathrm{kIU} / \mathrm{L}$ after treatment (normal $<120 \mathrm{kIU} / \mathrm{L}$ ) and at this time the skin test was negative. 24 hours after RIT the serum IgG had risen to $799 \mathrm{kIU} / \mathrm{L}$. These results suggest that plasmapheresis does not completely remove $\operatorname{IgE}$, and the residual $\operatorname{IgE}$ may have caused the hypersensitivity reaction. A second mechanism for immune complex formation may have been rapid generation of anti-mouse $\operatorname{IgG}$ antibodies produced by circulating memory cells.

We conclude that plasmapheresis cannot be relied upon to remove all HAMA after RIT, and that column chromatography can identify immune complexes undetectable by immunoassay. This test may be useful in identifying those patients at risk from hypersensitivity reactions when RIT is repeated.
Acknowledgment This work was funded by the Cancer Research Campaign.

\section{REFERENCES}

1 Ledermann JA, Begent RHJ, Bagshaw KD, et al. Repeated antitumour antibody therapy in man with suppression of the host response by cyclosporin A. Br J Cancer 1988;58:654-7

2 Kuus-Rachel K, Graver LS, Korawvodin LM, et al. Will immunogenicity limit the use, efficacy and future development of therapeutic monoclonal antibodies. Clin Diagn Lab Immunol 1994;1: $365-72$

3 Ledermann JA, Begent RHJ, Maassof C, et al. A phase 1 study of repeated therapy with radiolabelled antibody to carcinoembryonic antigen using intermittent or continuous administration of cyclosporin $\mathrm{A}$ to suppress the immune response. Int $J$ Cancer 1991;47:659-64

4 Zimmer AM, Rosen ST, Spies SM, et al. Radioimmunotherapy of patients with cutaneous T-cell lymphoma using and iodine-131-labelled monoclonal antibody: analysis of retreatment following plasmapheresis. J Nucl Med 1988;29:174-80

5 Pedley RB, Boden J, Keep PA, Harwood PJ, Green AJ, Rogers GT. Relationship between tumour size and uptake of radiolabelled antiCEA antibody in a colon tumour xenograft. Eur J Nucl Med 1987;13: 197-202

6 Adam T. Radioiodination for therapy. Ann Clin Biochem 1989;26(part 3):244-5 


\section{Dipyridamole in the treatment of a neonate with persistent pulmonary hypertension}

\author{
S Worwag MRCP H Mulla MRPharmS ${ }^{1}$ \\ D Luyt MRCP R K Firmin FRCS
}

$J$ J Soc Med 2000;93:77-78

In persistent pulmonary hypertension of the newborn (PPHN) a sustained rise in pulmonary vascular resistance diverts blood from the lungs, causing a ventilation-perfusion mismatch. Pulmonary vasodilatation cannot be relieved without correction of the resultant hypoxia and acidosis and conventional treatments include mechanical ventilation (to produce hyperoxia and hypocapnia), administration of bicarbonate and inotropic agents, intravascular volume support, and normalization of serum electrolytes and glucose. If these fail, others include magnesium sulphate, prostacyclin, inhaled nitric oxide (iNO), dipyridamole, high-frequency ventilation and extracorporeal membrane oxygenation (ECMO).

Use of dipyridamole has been described only in conjunction with iNO. We have used it as sole therapy.

\section{CASE HISTORY}

A male baby, born at term, was admitted with PPHN on day 1 of life for venovenous ECMO after failure of conventional treatment. He was severely asphyxiated at birth, with Apgar scores of 1 and 3 at 1 and 5 minutes and initial arterial blood $\mathrm{pH} 6.9, \mathrm{PaO}_{2} 3.23 \mathrm{kPa}$ and base deficit -18.2. He was treated with mechanical ventilation $\left(\mathrm{FiO}_{2}\right.$ 1.0 , pressure $40 / 5$ and respiratory rate $60 / \mathrm{min}$ ) and intermittent hand-bagging to maintain oxygen saturations $>70 \%$, intravenous magnesium sulphate, iNO, dopamine and artificial surfactant. Before transfer to our hospital for ECMO his oxygen index was 43 with arterial blood $\mathrm{pH}$ 7.27, $\mathrm{PaO}_{2} 5.2 \mathrm{kPa}, \mathrm{PaCO}_{2} 3.56 \mathrm{kPa}$ and base deficit -12 .

Echocardiography before ECMO revealed normal cardiac anatomy but a large unrestrictive patent ductus arteriosus with flow from right to left indicating

Departments of Paediatric Cardiology and ${ }^{1}$ Pharmacy, Glenfield Hospital NHS Trust, Leicester, UK

Correspondence to: Hussain Mulla, Department of Pharmacy, Glenfield Hospital NHS Trust, Leicester LE3 9QP, UK

E-mail: Hussain.mulla@glenfield-tr.trent.nhs.uk suprasystemic pulmonary artery pressures. During the first week of ECMO, pulmonary artery pressures remained suprasystemic. On day 7 he was treated with iNO (up to $80 \mathrm{ppm}$ ) and prostacyclin infusion. These had no effect on pulmonary artery pressure and were stopped after 24 hours; dipyridamole was then started at a dose of $4 \mathrm{mg} / \mathrm{kg}$ intravenously twice daily.

Echocardiography the next day showed a fall in pulmonary artery pressure to systemic levels. In the ensuing days the baby was weaned off life support and ECMO was discontinued on day 14. Echocardiography after ECMO showed a small restrictive patent ductus with mainly left to right flow and pulmonary artery pressures $20 \mathrm{mmHg}$ lower than systemic. After ECMO he remained stable on low mechanical ventilatory support. Dipyridamole was continued for 4 days and then slowly withdrawn over a further 4 days during which his pulmonary artery pressures remained normal. However, repeat echocardiography 4 days after discontinuation of dipyridamole showed pulmonary artery pressures again suprasystemic. These findings contradicted his clinical picture since he remained well with progressively declining ventilatory requirements. Dipyridamole was restarted and echocardiography 2 days later showed bidirectional ductal flow, although predominantly left to right, indicating equal pulmonary artery and systemic pressures. Dipyridamole was continued for a further 10 days during which he was successfully extubated. Echocardiography at one month of age, when all treatment had been stopped, showed subsystemic pulmonary artery pressures. He was discharged well, back to the referring hospital.

\section{COMMENT}

Dipyridamole, which reduces pulmonary artery pressure and pulmonary vascular resistance in many diseases associated with pulmonary hypertension, is thought to act by inhibiting cyclic guanine monophosphate (cGMP) specific phosphodiesterase. Endogenous and iNO-induced pulmonary vasodilatation is mediated through increased cGMP production in vascular smooth muscle ${ }^{1}$. Dipyridamole inhibition of phosphodiesterase inactivation of cGMP may increase both the potency and the duration of vasodilatation by increasing the concentration of cGMP in smooth muscle cells ${ }^{2}$. Dipyridamole also inhibits platelet adhesion and aggregation probably through increased intraplatelet cyclic adenosine monophosphate. Mild bleeding, if dipyridamole is used in conjunction with other anticoagulants, is a potential side effect.

Experiments in animals and case reports in man indicate that dipyridamole can reduce pulmonary vascular resistance in PPHN either by augmenting the response to iNO or by reducing rebound hypertension on its withdrawal ${ }^{3-5}$. 


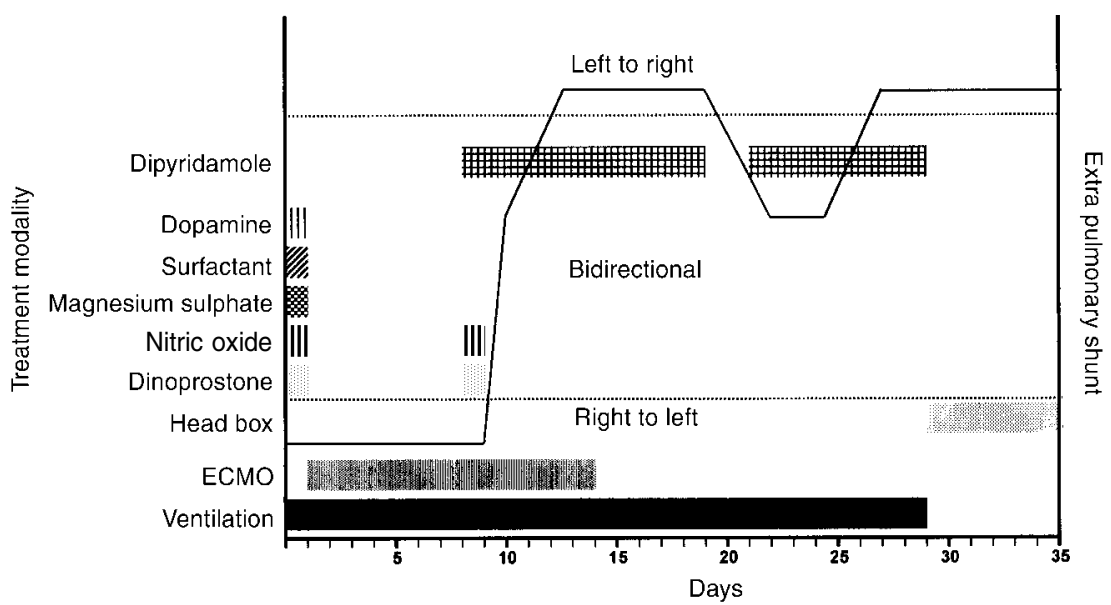

Figure 1 Effects of various treatment modalities on extrapulmonary shunting
Similar effects were observed in pulmonary hypertension following surgery for congenital cardiac disorders and in childhood primary pulmonary hypertension ${ }^{6}$. Dipyridamole is not widely used in pulmonary hypertension but our success with sole therapy, coupled with previous reports, suggests that it merits further investigation, at a time when the efficacy of iNO is in doubt.

\section{REFERENCES}

1 Griffith TM, Edwards DH, Lewis MS, Henderson AH. Evidence that cyclic guanosine monophosphate (cGMP) moderates endotheliumdependent relaxation. Eur J Pharmacol 1985;112:195-202

\section{Two aorto-iliac bypass graft infections associated with appendicitis}

\section{R D Brierly FRCS C J L Strachan MD FRCS}

J R Soc Med 2000;93:78-80

The most common source of graft prosthesis infection after vascular reconstructive surgery is the skin flora, but infection can also arise from an intra-abdominal inflammatory event.

\section{CASE HISTORIES}

\section{Case 1}

A man aged 77 had his $9 \mathrm{~cm}$ leaking abdominal aortic aneurysm repaired with an aorto-iliac graft. 4 years later he

Department of Surgery, Royal Sussex County Hospital, Brighton, UK
2 Ziegler JW, Ivy DD, Fox JJ, Kinsella JP, Clarke WR, Abman SH. Dipyridamole, a cGMP phosphodiesterase inhibitor causes pulmonary vasodilation in the ovine fetus. Am J Physiol 1995;269:H473-9

3 Al-Alaiyan, Al Omran, Dyer D. The use of phosphodiesterase inhibitor (dipyridamole) to wean from inhaled nitric oxide. Intent Car Med 1996;22:1093-5

4 Ivy DD, Kinsella JP, Ziegler JW, Abman SH. Dipyridamole attenuates rebound pulmonary hypertension after inhaled nitric oxide withdrawal in postoperative congenital heart disease. J Thorac Cardiovasc Surg 1998;115:875-82

5 Kinsella JP, Torielli F, Ziegler JW, Ivy DD, Abman SH. Dipyridamole augmentation of response to nitric oxide. Lancet 1995;346:647-8

6 Ivy DD, Ziegler JW, Kinsella JP, Wiggins JW, Abman SH. Haemodynamic effects of dypyridamole and inhaled nitric oxide in pediatric patients with pulmonary hypertension. Chest 1998;114(1 suppl):17S

was referred with a few days' history of central abdominal pain, anaemia and melaena. On examination he had a tender mass in the right iliac fossa and a bleeding duodenal ulcer was found on endoscopy. Leukocyte count was $26 \times 10^{9} / \mathrm{L}$ and blood cultures grew Klebsiella and Escherichia coli; he was started on intravenous cefotaxime. After he passed a further $400 \mathrm{~mL}$ fresh blood per rectum, he was taken to theatre. At laparotomy pus was found seeping from the proximal graft suture line and below was a secondary aorto-duodenal fistula. The appendix was closely adherent to the underlying graft, which was bile-stained. The right limb was thrombosed within an envelope of pus. Proximally, a loop of ileum also had a $1 \mathrm{~cm}$ diameter paraprosthetic contact with the right limb (Figure 1).

The fistulae were closed and appendectomy was performed. Histological examination revealed granulation tissue on the external surface of the appendix, presumably associated with the paraprosthetic fistula, and chronic active appendicitis. A right axillo-bifemoral bypass was performed before removal of the infected prosthesis. The bed of the infected graft was irrigated with aqueous povidone iodine. The patient was readmitted two months later with an abscess in his right thigh which drained $600 \mathrm{~mL}$ of pus containing E. coli, and 


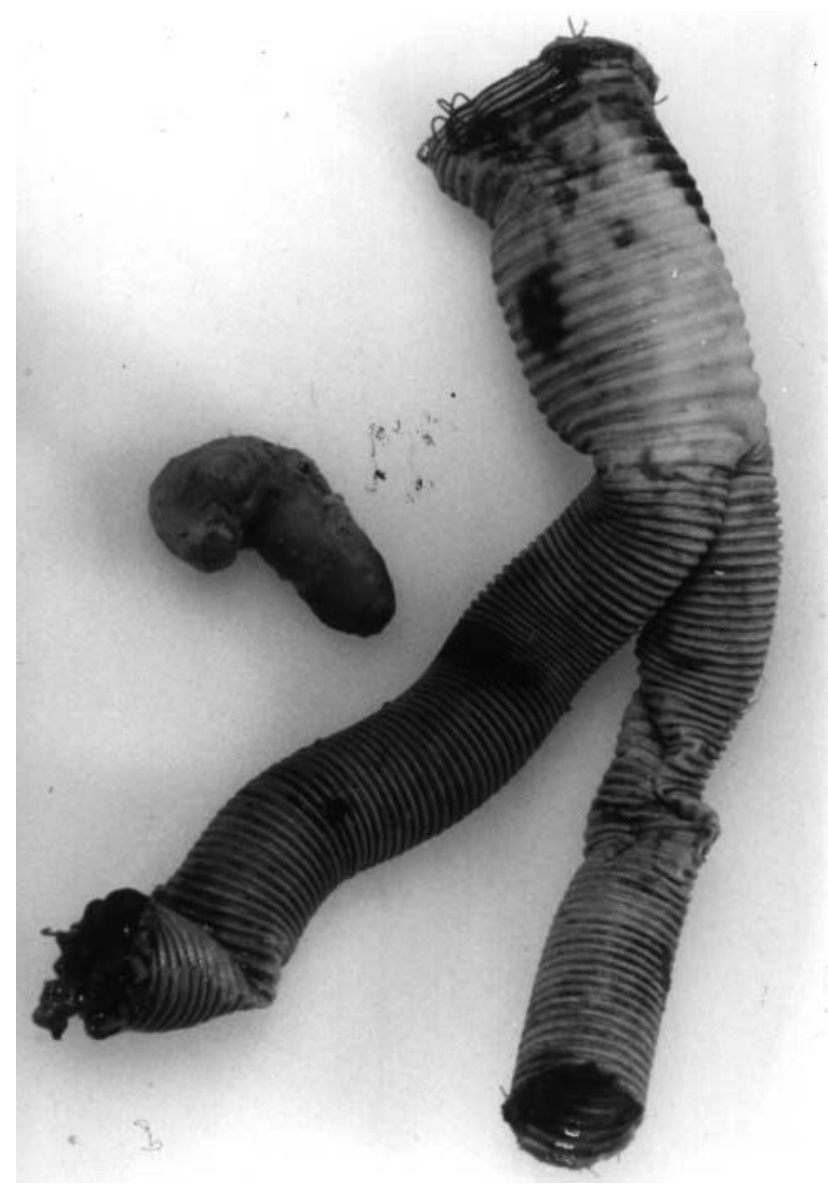

Figure 1 The excised aorto-iliac graft has bile staining at the proximal suture line and also where the appendix was closely adherent with the right limb of the graft

he was treated with netilmicin. He died four weeks later from bronchopneumonia.

\section{Case B}

A 59-year-old non-insulin-dependent diabetic patient with ischaemic heart disease underwent an emergency aortobifemoral graft for a ruptured abdominal aortic aneurysm. 14 years later he was admitted with acute ischaemia of the right leg secondary to thrombosis of the right graft limb. A successful embolectomy was performed. Postoperatively E. coli grew from blood culture and wound swab. This occult infection was treated with gentamicin and his fever settled. He was readmitted four months later with an abscess in the right groin, and an underlying graft infection was suspected. Doppler pressures, intravenous digital subtraction angiography and leukocyte count were all normal but a technetium-radiolabelled leukocyte scan demonstrated an infected 'hot' right limb of the graft (Figure 2). The groin and right pelvis were explored and a tunnel of pus was found from the groin up to a point $5 \mathrm{~cm}$ below the graft bifurcation. The tip of the appendix was

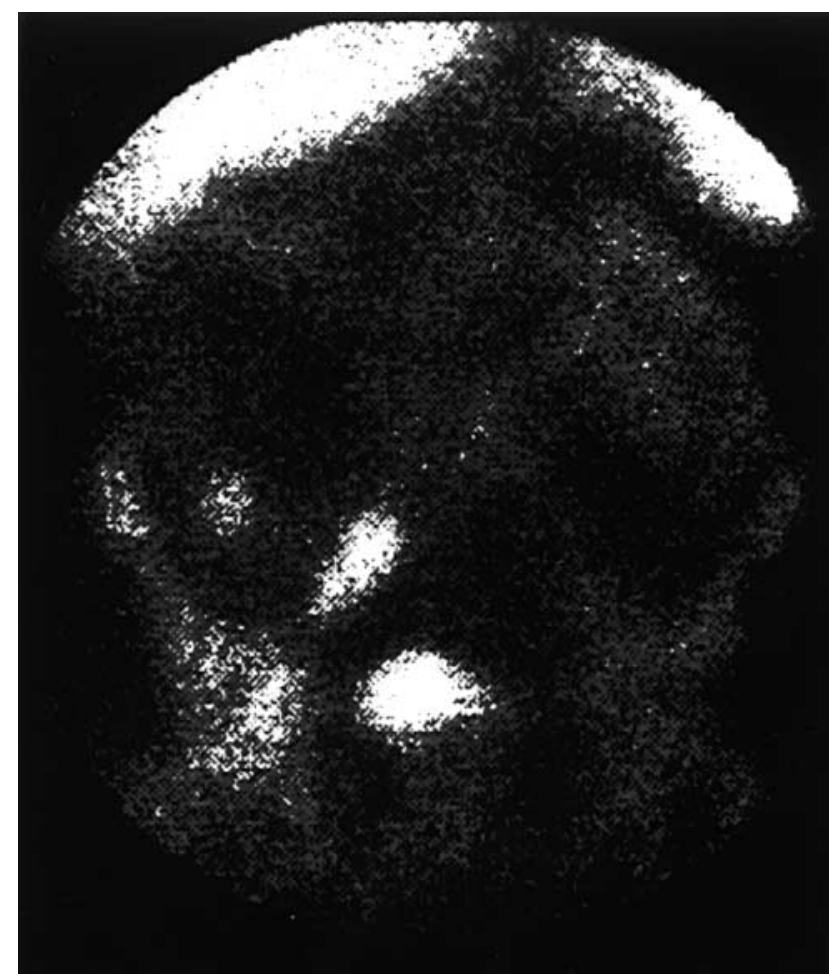

Figure 2 Technetium radio-labelled white cell scan demonstrates a 'hot spot' consistent with an infected right limb of the graft

clearly adherent to the graft limb, and the underlying graft was bile-stained. Histological examination of the appendix revealed chronic active appendicitis. The right limb of the graft was excised and a Fluoropassiv graft soaked in rifampicin $(60 \mathrm{mg} / \mathrm{mL})$ was taken from the graft stump, through the obturator foramen, deep to the adductors, to the upper popliteal artery. The right common femoral artery was closed and a gentamicin irrigation system was left in the infected bed. The excised graft and blood cultures grew E. coli and Pseudomonas sp. He was treated with intravenous imipenem and gentamicin and was discharged four weeks later. One year postoperatively he was fit and well.

\section{COMMENT}

There are two previous reports of fistulous connections between the appendix and a synthetic bypass graft $^{1,2}$, and two cases of an infected abdominal aortic aneurysm secondary to appendix abscess have also been described ${ }^{3,4}$. To our knowledge, there has been only one previous report of a closed aorto-femoral graft infection secondary to appendicitis ${ }^{5}$.

In our case 1, as well as a graft enteric fistula between duodenum and graft, there were two graft enteric erosions ${ }^{6}$ between appendix, ileum and graft. In this patient, the closely adherent appendix was not necessarily the cause of infection but might have become inflamed because of sepsis 
about the graft. In case 2 there was a single graft enteric erosion between appendix and graft.

These cases emphasize that appendicitis could well be the origin of very late Gram-negative graft infection when E. coli is cultured from blood or wounds.

Technetium white cell scanning, not yet available when the first patient was seen, can be useful in determining the site of graft infection. In case 2, knowledge that the infection was localized allowed excision to be limited to only one graft limb, avoiding the high risk of mortality associated with removal of the entire graft. These cases constitute a further warning that the appendix should never be left in close proximity to a graft or tunnel.

\section{Bilateral sixth and fourth cranial nerve palsies in idiopathic intracranial hypertension}

\section{N Patton MB S Beatty MB I C Lloyd FRCS FRCOphth}

J R Soc Med 2000;93:80-81

Idiopathic intracranial hypertension (IIH) is characterized by raised intracranial pressure in the presence of normal cerebrospinal fluid composition and unremarkable neuroradiological studies ${ }^{1}$. Sixth cranial nerve palsy is the most commonly described oculomotor abnormality seen in association with $\mathrm{IIH}^{2}$, although fourth cranial nerve palsies have also been reported ${ }^{3}$. Simultaneous bilateral fourth and sixth cranial nerve palsies have not previously been described in IIH.

\section{CASE HISTORY}

A boy aged 15 was referred with a two-week history of headaches, somnolence, intermittent vomiting and diplopia. Before this he had been fit and well. Other than obesity, general physical examination showed nothing of note. On visual assessment Snellen acuity was $6 / 6$ bilaterally but there was obvious papilloedema. Findings on orthoptic evaluation included: limitation of abduction of both eyes; underaction of the right eye and left eye on laevodepression and dextrodepression, respectively; overaction of the right and left eye on laevoelevation and dextroelevation,

Department of Ophthalmology, Manchester Royal Eye Hospital, Oxford Road, Manchester M13 9WH, UK

Correspondence to: Dr N Patton

\section{REFERENCES}

1 Tyson RR, Maier WP, Di Pietrantonio S. Ilio-appendiceal fistula following Dacron aortic graft. Am Surg 1969;35:241-3

2 Kitzmiller JW, Robb HJ, Barkal D, Clift D, Klein S, Madrazo A. Iliac appendiceal fistula: case presentation and review of management. $J$ Vasc Surg 1984;1:695-6

3 Mostovych M, Johnson L, Cambria RP. Aortic sepsis from an appendiceal abscess. Cardiovasc Surg 1994;2:67-9

4 Jewkes AJ, Black JJ. Infection of an abdominal aortic aneurysm from an appendix abscess. J Cardiovasc Surg 1989;30:870-2

5 Krupski WC, Mitchell RA, Gewertz BL, Fry WJ. Appendicitis and aortofemoral graft infection. Arch Surg 1979;114:969

6 Bunt TJ. Overview of graft-enteric fistula and erosions. In: Bunt TJ, ed. Vascular Graft Infections. New York: Armonk Futura, 1994:287-313

respectively; a right hypertropia on left gaze; a left hypertropia on right gaze; and a V-pattern esotropia (Figure 1). The clinical findings were suggestive of bilateral fourth and sixth cranial nerve palsies, corroborated by the Hess chart. Enlarged blind spots were demonstrable on Goldmann kinetic perimetry.

Computed tomographic and magnetic resonance brain scans were essentially normal, with no neuroradiological evidence of raised intracranial pressure. Analysis of cerebrospinal fluid revealed no abnormality, but the opening pressure was high $\left(28 \mathrm{~cm} \mathrm{H}_{2} \mathrm{O}\right)$.

In view of the above findings, idiopathic intracranial hypertension was diagnosed. Ocular and non-ocular symptoms and signs resolved completely after a course of oral acetazolamide $125 \mathrm{mg}$ twice daily and a successful programme of weight reduction.

\section{COMMENT}

Sixth cranial nerve palsy has a well described association with idiopathic intracranial hypertension and is frequently bilateral, especially in young patients. Of 10 paediatric cases of IIH recently reported, sixth cranial nerve palsies were present in 6 (4 bilateral and 2 unilateral $)^{2}$. However, raised intracranial pressure is frequently overlooked as a cause of fourth cranial nerve palsy. Speer et al. ${ }^{3}$ recently reported on 3 young patients who had unilateral fourth cranial nerve deficits associated with $\mathrm{IIH}$, but only one had a coexisting sixth nerve palsy. There is one account of bilateral superior oblique palsies in association with $\mathrm{IIH}^{4}$, but the authors concede that the vertical deviation in that case may have been due to skew deviation and the Hess chart did not support a diagnosis of bilateral superior oblique palsies.

The clinical findings suggestive of bilateral superior oblique palsies in our patient included underaction of right eye and left eye on laevodepression and dextrodepression, respectively. The Hess chart confirmed bilateral underaction of the superior obliques and overaction of the 


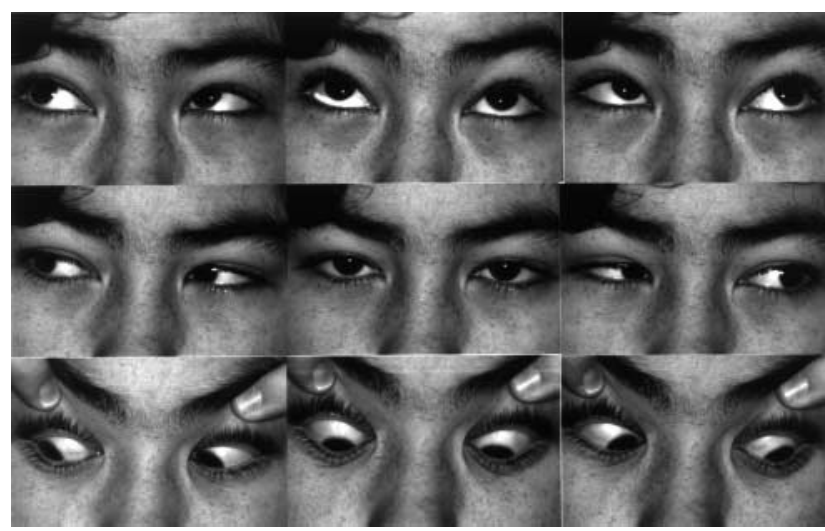

Figure 1 Nine positions of gaze in patient with idiopathic intracranial hypertension

Note the limitation of abduction of the right and left eye, the underaction of the right superior oblique in laevodepression, underaction of the left superior oblique in dextrodepression and the $\mathrm{V}$-pattern esotropia

inferior recti, corroborating the diagnosis. During the initial clinical examination the fourth cranial nerve palsies were not identified, for two reasons. First, bilateral superior oblique palsies present a particular diagnostic challenge to the clinician ${ }^{5}$ and our case exhibited subtle partial fourth cranial nerve palsies. Second, the convergent squint on downgaze was mistakenly attributed to the concurrent sixth cranial nerve palsies. It is possible, therefore, that transient bilateral fourth cranial nerve palsies are frequently missed in association with IIH.

This case illustrates the importance of fourth cranial nerve palsy as a false localizing sign in raised intracranial pressure and indicates a need to revise the modified Dandy criteria for diagnosis of IIH, which do not allow for any focal neurological deficit other than a sixth cranial nerve palsy $^{2}$. The complete recovery of the fourth and sixth cranial nerve palsies after treatment indicates that these ocular abnormalities are false localizing signs. The exact mechanism for the fourth nerve palsy remains uncertain but one possibility is compression of the nerve as it emerges from the superior medullary velum of the fourth ventricle. Friedman et al. ${ }^{6}$ postulate that increased intracranial pressure results in displacement or distortion of brainstem structures including the cranial nerves. Bell et al. ${ }^{7}$ propose that a change in cerebrospinal fluid dynamics can distort intracranial anatomy and thus transiently compress the fourth cranial nerve. The trochlear nerve has the longest intracranial course $(75 \mathrm{~mm})$ of all cranial nerves so we should not be surprised that its function is affected by fluctuations in intracranial pressure.

\section{REFERENCES}

1 Lessell S. Pediatric pseudotumor cerebri (idiopathic intracranial hypertension). Surv Ophthalmol 1992;37:155-66

2 Cinciripini GS, Donahue S, Borchert MS. Idiopathic intracranial hypertension in prepubertal patients: characteristics, treatment, and outcome. Am J Ophthalmol 1999;127:178-82

3 Speer C, Pearlman J, Philips PH, et al. Fourth cranial nerve palsy in pediatric patients with pseudotumor cerebri. Am J Ophthalmol 1999; 127:236-7

4 Baker RS, Buncic JR. Vertical ocular motility disturbance in pseudotumor cerebri. J Clin Neuro-ophthalmol 1985;5:41-4

5 Pollard ZF. Classification and treatment of bilateral superior oblique palsy. Ann Ophthalmol 1985;17:127-31

6 Friedman DI, Forman S, Levi L, et al. Unusual ocular motility disturbances with increased intracranial pressure. Neurology 1998;50:1893-6

7 Bell RWD, McIlwaine GG, Lueck CJ. An unusual cause of intermittent vertical diplopia. Eye 1999;13:387-8

\section{Snoring with sleep apnoea: deceptive appearances}

\section{Srinivasan DLO FRCS J E Davies FRCS}

J R Soc Med 2000;93:81-82

Obstructive sleep apnoea is the most common type of sleep apnoea, with cessation of airflow despite continued

Ear, Nose and Throat Department, Leighton Hospital, Crewe CW1 4QJ, UK

Correspondence to: Mr V Srinivasan, 40 Childwall Mount Road, Liverpool L16 7PL, UK

E-mail: cheenu@compuserve.com respiratory effort. Though any space occupying lesion from nostril to glottis can predispose to snoring and obstructive sleep apnoea, most adult snorers have no such lesion.

\section{CASE HISTORY}

A man aged 57 sought advice because of snoring and intermittent choking episodes for the past six months. His general practitioner referred him to the regional sleep laboratory, where obstructive sleep apnoea was diagnosed and he was managed with continuous positive airway pressure (CPAP). The snoring gradually became worse and six months later he began to experience difficulty with breathing, which became noisy. On questioning in the ear, nose and throat department he revealed that for 3 years he had had intermittent dysphagia for solid food such as bread and meat. He had mild stertor (noisy breathing due to obstruction of the pharyngeal space above the larynx) and 


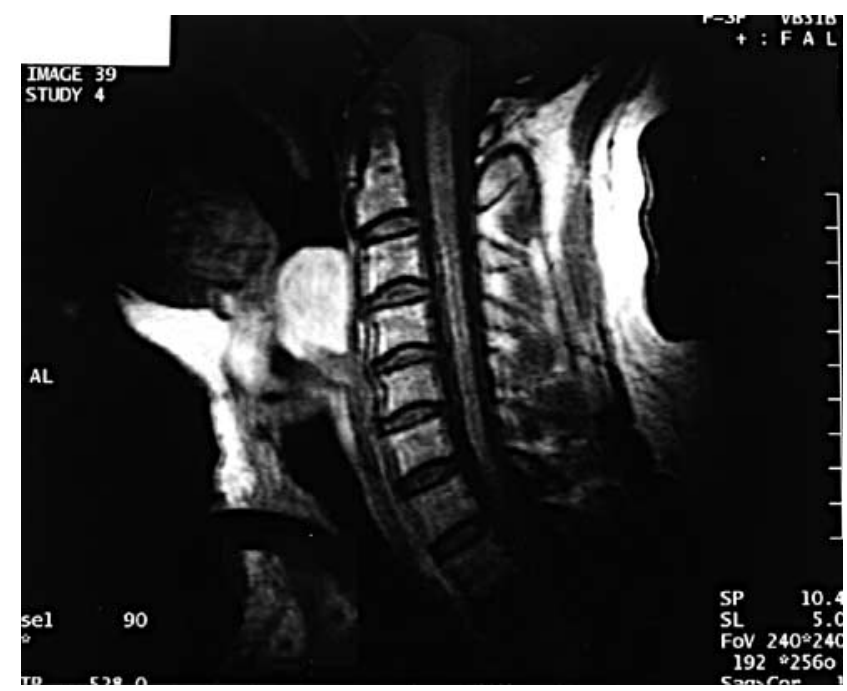

Figure 1 Magnetic resonance scan of neck, sagittal section

dysphonia. Fibreoptic nasolaryngoscopy showed a smoothsurfaced swelling in the hypopharynx, obstructing the laryngeal inlet.

Urgent tracheostomy was done to secure the airway, since the patient was in danger of total airway obstruction. On rigid endoscopy of the pharynx the mass was found to be soft and pedunculated, probably arising from the posterior pharyngeal wall at the level of the arytenoids. The clinical diagnosis was lipoma. Magnetic resonance imaging showed a well defined mass arising from the posterior wall of the hypopharynx, with uniform fat signal intensity (Figure 1). This was excised via a lateral pharyngotomy. The patient was extubated the next day and the tracheostome was allowed to heal spontaneously. Histological examination confirmed that the lesion was a fibrolipoma. The snoring and sleep apnoea resolved completely and the patient returned his CPAP machine to the hospital.

\section{COMMENT}

Snoring is the cardinal symptom of obstructive sleep apnoea. In a patient with suspected sleep apnoea, appropriate investigations may include overnight pulse oximetry, polysomnography, lateral cephalometry, pharyngeal computed tomography or magnetic resonance scanning and sleep nasoendoscopy. When there are
Box 1 Mechanical causes to be excluded in obstructive sleep apnoea

- Nose

Nasal polyps; septal deviation with inferior turbinate hypertrophy; tumours

- Pharynx

Enlarged adenoids; enlarged tonsils; retropharyngeal mass; macroglossia; neoplasms

- Larynx

Cysts; haemangiomas; tumours

additional symptoms referable to the upper aerodigestive tract such as nasal obstruction, dysphonia and dysphagia, detailed ENT examination, including endoscopy of the larynx and pharynx, is warranted. Conditions to be looked for include nasal polyps, enlarged adenoids, enlarged tonsils, macroglossia and neoplasms (Box 1). Neoplasms of the pharynx and larynx seldom cause snoring and sleep apnoea unless they are large, and usually they will show themselves with other symptoms such as dysphonia and dysphagia. Our patient had dysphagia for 3 years before the onset of snoring and sleep apnoea but did not mention this initially because it was not disabling.

Lipomas in the larynx and pharynx are very rare ${ }^{1}$. The initial symptoms of a hypopharyngeal lipoma include a sensation of lump in the throat and dysphagia, and subsequent laryngeal inlet obstruction can result in snoring, muffled speech and stridor. Sudden asphyxia and death have been reported from a pedunculated lipoma arising from the posterior pharyngeal wall ${ }^{2}$. Magnetic resonance imaging is helpful in assessing the extent and nature of such tumours. The treatment of choice is surgery, and small tumours can be removed endoscopically if the base or pedicle is visible.

Patients referred for snoring should specifically be questioned for ENT symptoms and, if these are present, should have a nose and throat examination including laryngoscopy.

\section{REFERENCES}

1 Eckel HE, Jungehulsing M. Lipoma of the hypopharynx: preoperative diagnosis and transoral resection. J Laryngol Otol 1994;108:174-7

2 Fyfe B, Mittleman RE. Hypopharyngeal lipoma as cause for sudden asphyxial death. Am J Forens Med Pathol 1991;12:82-4 


\section{Sclerosing mediastinitis with aortic valve regurgitation and aortic root dilatation}

\author{
G St Krasopoulos MRCS M Ibrahim FRCS \\ G Venn FRCS
}

J R Soc Med 2000;93:83

Sclerosing mediastinitis is an uncommon disease associated with multiple clinical syndromes. The cause is probably an abnormal fibroproliferative response to an inflammatory stimulus. Erosion and entrapment of mediastinal structures can require specific surgical interventions.

\section{CASE HISTORY}

An Afro-Caribbean man aged 46 was seen with a short history of dyspnoea on minimal exertion. He also reported persisting headache and recent memory loss. He had a history of therapy-resistant hypertension with stage-2 hypertensive nephropathy and chronic renal failure, and of sleep apnoea. On examination he had florid signs of aortic regurgitation, he was in biventricular failure and blood pressure was $210 / 150 \mathrm{mmHg}$. Transthoracic echocardiography and left-sided cardiac catheterization confirmed severe aortic regurgitation and revealed dilatation of the ascending aorta (sinus of Valsalva $5 \mathrm{~cm}$, sinotubular junction $4.9 \mathrm{~cm}$, arch $2.6 \mathrm{~cm}$ ). Computed tomography (Figure 1) showed an enlarged ascending aorta, bilateral pleural effusions and a small pericardial effusion. When examined postoperatively, the scan was also seen to show an extensive area of connective tissue around the aorta.

At operation the aortic root appeared to be encompassed by dense inflammatory tissue, from which the root was excised and replaced with a $27 \mathrm{~mm}$ Carbomedics valved conduit. The histological appearances of the excised tissue were consistent with sclerosing mediastinitis. Computed tomography of the abdomen and brain did not reveal any other sites of connective tissue proliferation; thyroid function was normal. The patient was discharged home after ten days.

Guy's and St Thomas' Hospitals NHS Trust, London, UK

Correspondence to: Mr G Krasopoulos, 45 Bywater Place, London SE16 1NE, UK

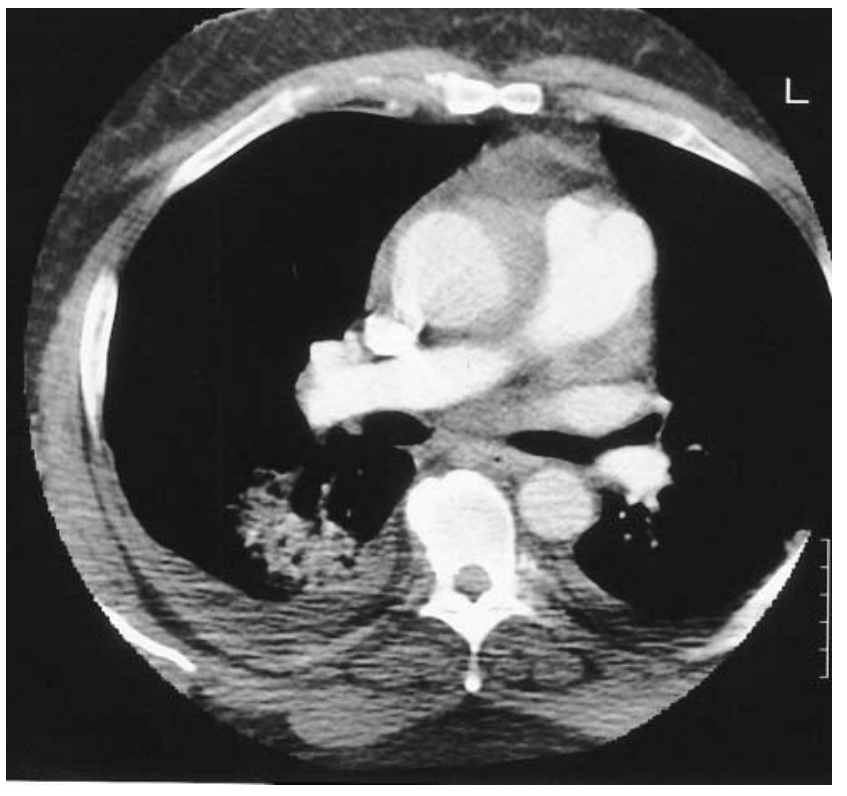

Figure 1 Computed tomographic scan of chest

\section{COMMENT}

The fibrous mass of sclerosing mediastinitis is typically located in the superior mediastinum, near the bifurcation of the trachea as well as in the pulmonary hila, and often extends into adjacent structures ${ }^{1}$. It is compression of vital structures and invasion by chronic inflammatory tissue that give rise to the various clinical syndromes. Vascular abnormalities are usually inconspicuous or absent ${ }^{2}$. Thus, our case was unusual in that the manifestations were related to the aortic valve and ascending aorta. Even more surprising is the fact that the aorta was dilated rather than compressed; such features do not seem to have been reported before.

Sclerosing mediastinitis is seen most commonly in areas where histoplasmosis is endemic ${ }^{2}$; other fungal and bacterial infections are associated with the condition ${ }^{2}$. The hyperreactive fibrous response is shared with collagenoses such as retroperitoneal fibrosis, Riedel's struma, sclerosing cholangitis, pseudotumour of the orbit and keloids ${ }^{1,3}$.

\section{REFERENCES}

1 Dunn EJ, Ulicny KS, Wright CB, Gottesman L. Surgical implications of sclerosing mediastinitis. Chest 1990;97:338-46

2 Dehner LP, Coffin CM. Idiopathic fibrosclerotic disorders and other inflammatory pseudotumors. Semin Diagn Pathol 1998;15:161-73

3 Comings DE, Skubi KB, Van Eyes J, Motulsky AG. Familial multifocal fibrosclerosis. Findings suggesting that retroperitoneal fibrosis, mediastinal fibrosis, sclerosing cholangitis, Riedel's thyroiditis and pseudotumour of the orbit may be different manifestations of a single disease. Ann Intern Med 1967;66:884-92 


\section{Chicken bone injury of the common bile duct}

\section{S Baldota MS FRCS C Breach MBBS B Murtuza FRCS \\ B El Houcheimi MBBS A Darzi MD FRCS \\ D J Hadjiminas MPhil}

J R Soc Med 2000;93:84

Injuries of the common bile duct caused by transluminal migration of foreign bodies can be hard to diagnose.

\section{CASE HISTORY}

A man aged 50 who had been travelling in Africa and South Central Asia reported a three-day history of intermittent right hypochondrial pain radiating to the back, with fever, rigors and jaundice. On admission he was pyrexial, moderately dehydrated, tachycardic and icteric with tenderness and localized guarding in the right hypochondrium. White cell count was $17.5 \times 10^{9} / \mathrm{L}$, serum bilirubin $25 \mu \mathrm{mol} / \mathrm{L}$, alanine aminotransferase $46 \mathrm{IU} / \mathrm{L}$, alkaline phosphatase $135 \mathrm{IU} / \mathrm{L}$ and amylase $135 \mathrm{IU} / \mathrm{L}$. Plain chest and abdominal radiographs were not informative, and an initial ultrasound revealed a normal gallbladder with a $6 \mathrm{~mm}$ common bile duct. Over the next 48 hours the signs of sepsis increased, with hypotension, tachycardia, dyspnoea, oliguria and right hypochondrial pain. Liver function tests worsened. These features indicated fulminant ascending cholangitis, which was managed with central venous monitoring, intravenous colloids and antibiotics (including tazocin, metronidazole and gentamicin). A computerized tomographic (CT) scan revealed a low attenuation area in segment IV of the liver consistent with a hepatic abscess,

Academic Surgical Unit, St Mary's Hospital and Imperial College School of Science Medicine \& Technology, London W2, UK

Correspondence to: S Baldota, Department of Surgery, St Mary's Hospital, London W2 1NY, UK aspiration of which yielded haemopurulent fluid. Blood tests for hepatitis and malaria were negative. A hydroxyl iminodiacetic acid scan revealed normal uptake in the gallbladder, and endoscopic retrograde cholangiopancreatography indicated that the biliary tree was non-obstructed. Hepatic abscess was diagnosed, but investigations including colonoscopy, stool culture, and an abdominal CT scan did not locate the original source of infection. A repeated ultrasound of the abdomen revealed an oedematous gallbladder. At laparoscopy a long fine object, later identified as a chicken bone, was seen penetrating the common bile duct, having perforated the first part of the anterior duodenal wall. The bone was removed, the common bile duct was repaired and a laparoscopic cholecystectomy was completed. The gallbladder contained no stones and the histological picture was of chronic inflammation.

\section{COMMENT}

Foreign-body perforation of the gastrointestinal tract occurs from the oesophagus ${ }^{1}$ to the rectum. In a series of eleven cases, fish, chicken or meat bones caused nine of the perforations ${ }^{2}$. Two cases similar to ours, with common bile duct or hepatic injury from antral or distal gastric perforation, have been reported over the last eighteen years ${ }^{3,4}$. Often the patient can offer no relevant history; Aird ${ }^{5}$ suggested that even a sharp object may go unnoticed by a patient with an upper denture plate affecting palatal sensation. In the absence of radiographic and other pointers, diagnostic laparoscopy may give the answer.

\section{REFERENCES}

1 Nandi P, Ong GB. Foreign body in the esophagus: review of 2394 cases. Br J Surg 1978;54:383-4

2 Ashby S, Hunter-Craig ID. Foreign body perforations of the gut. BrJ Surg 1967;65:5-9

3 Gay P, Gaddie D. Perforation of the stomach by fish bone producing delayed transient obstructive jaundice. Aust N Z J Surg 1993;63:826-7

4 Tsuboi K, Nakajima J, Yamamoto S, Nagao M, Nishimura K, Yoshii M. et al. A case of intrahepatic fish bone penetration possibility of preoperative diagnosis by CT scan. Nippon Geka Kokan 1981;50:899-903

5 Aird I. Companion in Surgical Studies. Edinburgh: Livingstone, 1958:831 


\section{Extrarectal mass: a tailgut cyst}

\author{
D Costello MA A Schofield MS FRCS ${ }^{1}$ \\ R Stirling FRCPath ${ }^{2} \quad \mathrm{~N}$ Theodorou MS FRCS ${ }^{1}$
}

J R Soc Med 2000;93:85-86

CLINICAL SECTION, 18 FEBRUARY 1999

The tailgut cyst or retrorectal cystic hamartoma is often an incidental finding but may cause chronic perirectal symptoms. Since carcinomatous degeneration has been described, complete surgical excision is advised.

\section{CASE HISTORY}

A woman aged 37 was referred with a retrorectal mass originally noted by obstetricians during childbirth. Two perineal explorations had been performed to drain the fluid filled mass. She now complained of intermittent discharge from a sinus behind the anus. On examination, there was a post-anal sinus but no perineal swelling. On rectal examination a soft midline swelling, separate from the rectum in the presacrococcygeal space, was palpable above the levator ani; overlying rectal mucosa was normal. Magnetic resonance imaging (MRI) showed a $3 \mathrm{~cm}$ diameter cyst above the pelvic floor.

At laparotomy the cystic lesion, densely adherent to the coccyx, was removed apparently intact. Histological examination revealed that it was a retrorectal cystic hamartoma or tailgut cyst, consisting of multiple cysts, most of which were lined with stratified squamous epithelium but others with glandular and transitional epithelium.

2 years later she again complained of a discharging perianal sinus. There was now a clearly palpable perineal swelling. Endoanal ultrasound and MRI (Figure 2) revealed a further cystic mass, but now below the levator muscles. A perineal approach allowed complete excision, and histological examination showed that this too was a tailgut cyst.

\section{COMMENT}

Tailgut cysts are embryological remnants of the hindgut. In normal development, the part of the tailgut distal to the

Imperial College of Science, Technology and Medicine at Charing Cross, Reynolds Building, St Dunstan's Road, London W6 8RF; 'Department of Gastrointestinal Surgery, Charing Cross Hospital, Fulham Palace Road, London W6 8RF; 'Department of Histopathology, West Middlesex University Hospital, Isleworth TW7 6RF, UK

Correspondence to: N Theodorou, Consultant Surgeon, 8th Floor East Wing, Department of Gastrointestinal Surgery, Charing Cross Hospital, Fulham Palace Road, London W6 8RF, UK

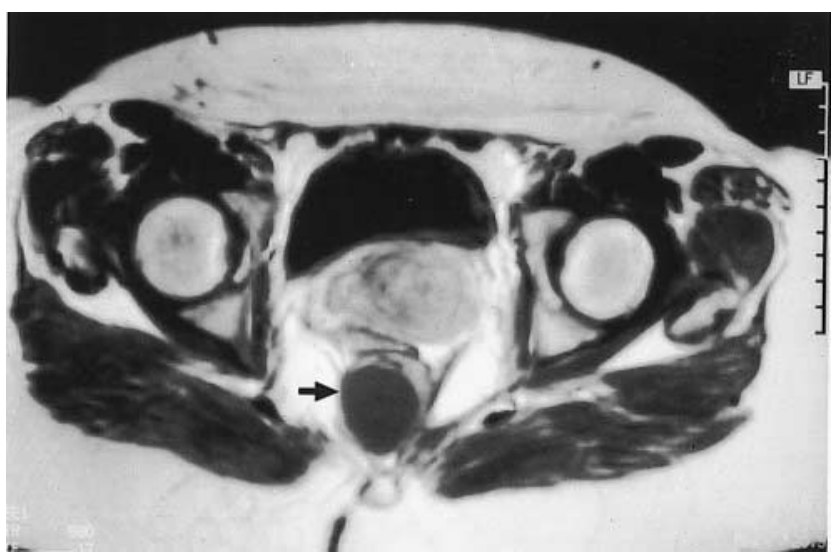

Figure 1 Axial T1-weighted magnetic resonance scan showing cystic mass (arrow) anterior to sacrum, and posterior to rectum

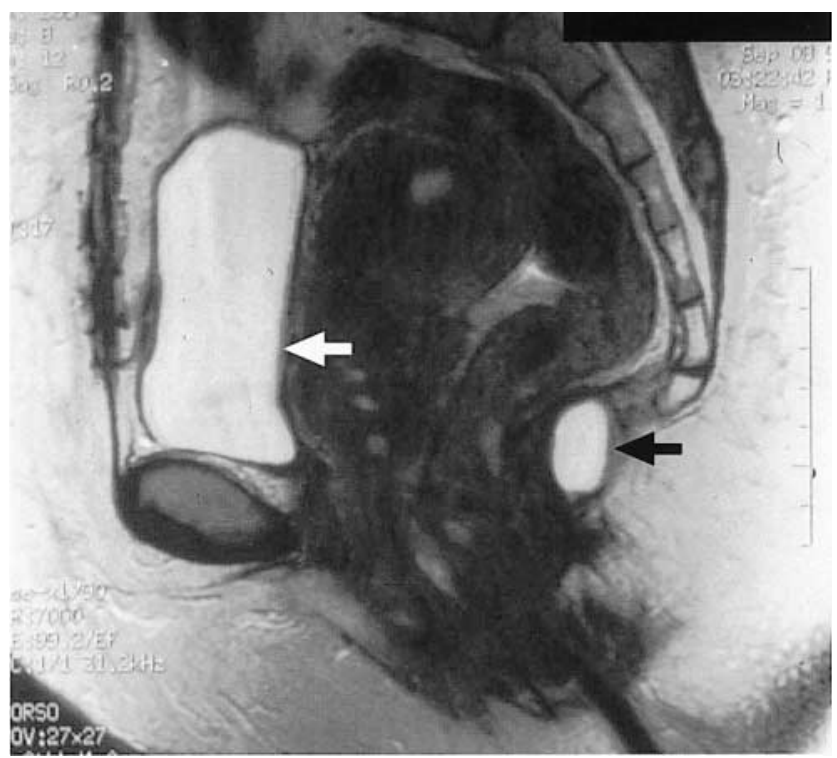

Figure 2 Sagittal T2-weighted magnetic resonance scan showing cystic mass (solid arrow). Open arrow points to bladder

invaginating anus is obliterated by around 56 days' gestation. These swellings are multicystic, and the cysts are lined with the different epithelial types normally found in the embryological gastrointestinal tract-stratified squamous, ciliated columnar, mucin-secreting columnar and transitional. Although benign, tailgut cysts occasionally undergo carcinomatous degeneration ${ }^{2}$.

These cystic tumours arising in the sacral region should be distinguished from dermoid cysts and duplication cysts of the rectum. Dermoid cysts are lined only with stratified squamous epithelium, and may contain hair or other mature tissues. Duplication cysts exhibit features of the adult gastrointestinal tract such as crypts and villi, which are absent in the fetus and therefore in the tailgut cyst.

Though often an incidental finding, tailgut cysts can cause discomfort on sitting, difficulty in opening bowels or urinary retention. The cyst may become infected and 
recurrent abscesses in the retrorectal space or repeated operations for fistula in ano may feature in the history. On physical examination there is always a midline dimple posterior to the anus, which may be mistaken for an anal fistula and may result from the pull of the filum terminale on the skin during early development ${ }^{3,4}$. Unusual perineal swellings are often treated as abscesses, and erroneous incision and drainage can lead to delays in diagnosis.

How do we explain the recurrence in this case? The probable explanation is that the original lesion was bilobed or dumbbell shaped, with one part above the levators connected by a small fistula to another below. Previous exploratory operations had decompressed the lower lobe, so two lobes were not seen on the original MRI scans. After removal of the upper lobe, the lower lobe gradually reaccumulated fluid and began discharging.

Before surgical operation on an unusual perineal swelling, views should be obtained by magnetic resonance and endoanal ultrasound both above and below the levators.

\section{REFERENCES}

1 Hjermstad BM, Helwig EB. Tailgut cysts - report of 53 cases. Am J Clin Pathol 1988;89:139-47

2 Rosai J. Ackerman's Surgical Pathology, 7thedn. St Louis: Mosby, 1989:1656

3 Levert LM, Van Rooyen W, Ven Den Bergen H. Cysts of the tailgut. Eur J Surg 1996;162:149-52

4 McDermott NC, Newman J. Tailgut cyst (retrorectal cystic hamartoma) with prominent glomus bodies. Histopathology 1991;18:265-6

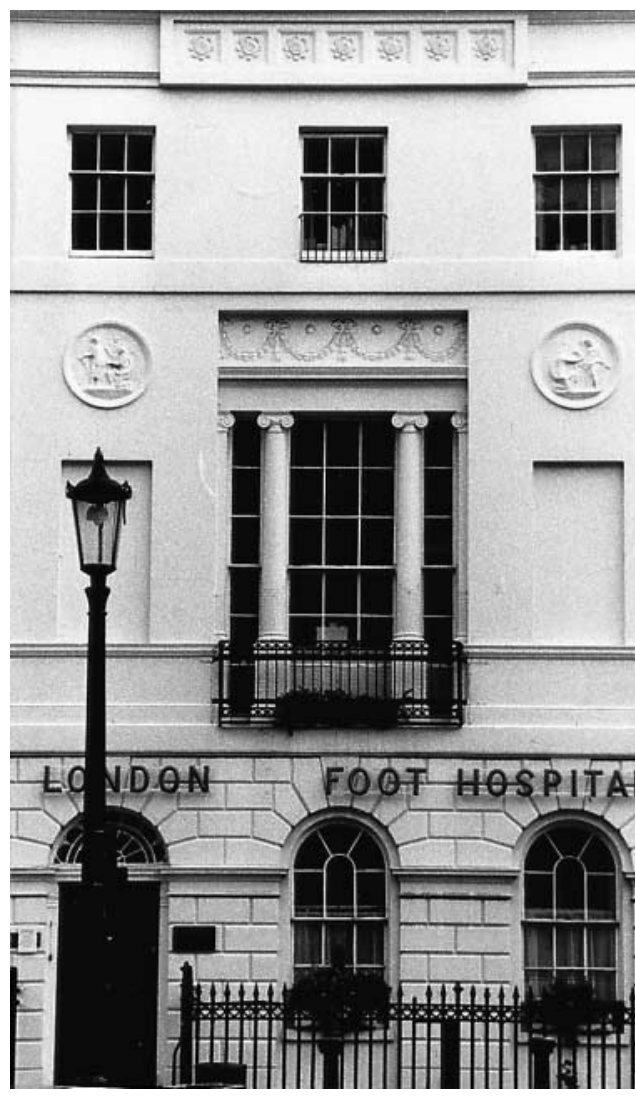

\section{Podiatric elegance in Fitzrovia}

Robert Adam (1728-1792) designed the houses on the south side of Fitzroy Square two of which serve the purposes of the London Foot Hospital. Architectural features shown in the illustration, as described in the Survey of London LCC 1949 (volume xxi, Tottenham Court Road and neighbourhood, The parish of St Pancras, part III), include a central window divided into three lights by Ionic shafts on pedestals supporting a plain lintel and stringcourse, above which is a frieze with swag ornament, the whole within a square-headed recess. This is flanked by shorter square-headed blind windows or recesses above a dado with cup and base mouldings. Above these are plaques showing classical figures. In the 19th century, converted houses were favoured as the premises of many new specialist hospitals founded at the time; by contrast, in the late 20th century, many former hospital buildings have been converted to domestic uses.

\section{Denis Gibbs}

